Int. J. Electrochem. Sci., 11 (2016) 9175 - 9191

\title{
Corrosion Inhibition Effect of Histidine and Its Derivatives Self-Assembled Films Formed of 304 Stainless Steel
}

\author{
Zhe Zhang ${ }^{1, *}$, Xiaodong Huang ${ }^{1}$, Ningchen Tian ${ }^{1}$, Fusong $N i^{1}$, Le Ruan ${ }^{1}, Y_{u z e n g}$ Lv $^{2}$, Ling $W u^{3}$ \\ ${ }^{1}$ Guangxi Key Laboratory of Electrochemical and Magneto-chemical Functional Materials, College of \\ Chemistry and Bioengineering, Guilin University of Technology, Guilin 541004, PR China \\ ${ }^{2}$ Engineering Research Center of Exploration for hidden Nonferrous and Precious Metal Ore Deposits, \\ Ministry of Education, 541004, PR China \\ ${ }^{3}$ School of Chemistry and Chemical Engineering, Shandong University, Jinan 250100, PR China \\ *E-mail: zhangzhe@ glut.edu.cn
}

doi: $10.20964 / 2016.11 .73$

Received: 10 March 2016 / Accepted: 19 September 2016 / Published: 10 October 2016

The histidine and its derivatives self-assembled (SA) films were prepared on the 304 stainless steel (SS) surface. EIS and potentiodynamic polarization curves measurements proved that these SA films could effectively protect SS against corrosion in 3.5\% $\mathrm{NaCl}$ solution, with a maximal protection efficiency of $94.24 \%$ achieved by Carbobenzyloxy-L-histidine film. XPS studies confirmed that Carbobenzyloxy-L-histidine molecule could adsorb on SS surface. The quantum chemical calculation and dynamic simulation provided the theoretical support about the inhibition mechanism.

Keywords: histidine; self-assembled films; 304 stainless steel; electrochemical techniques; XPS.

\section{FULL TEXT}

(C) 2016 The Authors. Published by ESG (www.electrochemsci.org). This article is an open access article distributed under the terms and conditions of the Creative Commons Attribution license (http://creativecommons.org/licenses/by/4.0/). 